\title{
Constitutive Relationships for Elastic Deformation of Clay Rock: Data Analysis
}

\author{
H. H. Liu · J. Rutqvist $\cdot$ J. T. Birkholzer
}

Received: 26 March 2010/Accepted: 20 December 2010/Published online: 6 January 2011

(C) The Author(s) 2011. This article is published with open access at Springerlink.com

\begin{abstract}
Geological repositories have been considered a feasible option worldwide for storing high-level nuclear waste. Clay rock is one of the rock types under consideration for such purposes, because of its favorable features to prevent radionuclide transport from the repository. Coupled hydromechanical processes have an important impact on the performance of a clay repository, and establishing constitutive relationships for modeling such processes are essential. In this study, we propose several constitutive relationships for elastic deformation in indurated clay rocks based on three recently developed concepts. First, when applying Hooke's law in clay rocks, true strain (rock volume change divided by the current rock volume), rather than engineering strain (rock volume change divided by unstressed rock volume), should be used, except when the degree of deformation is very small. In the latter case, the two strains will be practically identical. Second, because of its inherent heterogeneity, clay rock can be divided into two parts, a hard part and a soft part, with the hard part subject to a relatively small degree of deformation compared with the soft part. Third, for swelling rock like clay, effective stress needs to be generalized to include an additional term resulting from the swelling process. To evaluate our theoretical development, we analyze uniaxial test data for core samples of Opalinus clay and laboratory measurements of single fractures within macro-cracked Callovo-Oxfordian argillite samples subject to both confinement and water reduced swelling. The results from this evaluation indicate that our constitutive relationships can
\end{abstract}

H. H. Liu ( $₫)$ · J. Rutqvist · J. T. Birkholzer

Earth Science Division,

Lawrence Berkeley National Laboratory,

Berkeley, CA, USA

e-mail: hhliu@lbl.gov adequately represent the data and explain the related observations.

Keywords Constitutive model - Clay rock · Coupled processes

\section{Introduction}

Clay rock has been considered as a potential host rock for geological disposal of high-level nuclear waste throughout the world, because it has low permeability, low diffusion coefficient, high retention capacity for radionuclides, and the capability to self-seal fractures induced by tunnel excavation (Fouche et al. 2004; Patriarche et al. 2004; Meier et al. 2000; Barnichon and Volckaert 2003). Coupled hydraulic and mechanical processes have a significant impact on the long-term safety of a clay repository and are largely controlled by constitutive relationships for the host rock, or relationships among hydraulic and mechanical properties. The major objective of this note is to present and evaluate several physically based constitutive relationships for elastic deformation of the indurated clay rock (Tsang et al. 2005), with a focus on fractures. Note, however, that indurated clay rock also involves non-elastic deformation under certain conditions (Alonso and Alcoverro 2002). To the best of our knowledge, studies on constitutive relationships for fractures in clay rock are very rare in the literature.

\section{Constitutive Relationships}

The constitutive relationships discussed here builds on a newly proposed stress-strain relationship for elastic 
deformation of fractured rock (Liu et al. 2009), and a concept of internal swelling stress for coal seams that can involve swelling or shrinkage during $\mathrm{CO}_{2}$ sequestration (Liu and Rutqvist 2010).

The stress-strain relationship is fundamental for modeling mechanical deformation and the associated coupled processes in porous and fractured rock. To more accurately model elastic deformation in rocks, Liu et al. (2009) indicated that the current application of Hooke's law needs to be improved in several aspects. First, in Hooke's law, true strain (rock volume change divided by the current rock volume), rather than engineering strain (rock volume change divided by unstressed rock volume), should be used, except for small deformation. Second, because of its inherent heterogeneity, clay rock can be divided into two parts, a hard part and a soft part, with the hard part subject to relatively small deformation compared to the soft part. For an isotropic rock under uniform principal stresses, Liu et al. (2009) give a general elastic strain-stress $(\sigma)$ relationship (that is essentially phenomenological):

$$
-\frac{\mathrm{d} V}{V_{0}}=\gamma_{\mathrm{e}} \frac{\mathrm{d} \sigma}{K_{\mathrm{e}}}+\gamma_{\mathrm{t}} \exp \left(-\frac{\sigma}{K_{\mathrm{t}}}\right) \frac{\mathrm{d} \sigma}{K_{\mathrm{t}}}
$$

where $K_{\mathrm{e}}$ and $K_{\mathrm{t}}$ refer to bulk moduli for the hard and soft parts, respectively, and $V$ is rock volume. The parameters $\gamma_{\mathrm{e}}$ and $\gamma_{\mathrm{t}}$ are volumetric portions of hard and soft parts under unstressed conditions. Note that subscripts $0, e, t$ refer to zero stress condition, hard part and soft part, respectively, throughout this note. From the above equation, the bulk modulus $K=-V_{0} \frac{\mathrm{d} \sigma}{\mathrm{d} V}$ is given by

$K=\frac{1}{\frac{\gamma_{\mathrm{e}}}{K_{\mathrm{e}}}+\frac{\gamma_{\mathrm{t}}}{K_{\mathrm{t}}} \exp \left(-\frac{\sigma}{K_{\mathrm{t}}}\right)}$

Along the same line, Liu et al. (2009) derived a fracture aperture $(b)$-normal stress $\left(\sigma_{\mathrm{n}}\right)$ relation:

$b=b_{0, \mathrm{e}}\left(1-\frac{\sigma_{\mathrm{n}}}{E_{\mathrm{F}, \mathrm{e}}}\right)+b_{0, \mathrm{t}} \exp \left(-\frac{\sigma_{\mathrm{n}}}{E_{\mathrm{F}, \mathrm{t}}}\right)$

where $E$ refers to Young's modulus for this equation, subscript $F$ refers to fracture. Because fracture permeability is proportional to the cube of fracture aperture (under an assumption that fractures can be approximated as parallel plates), the fracture permeability $k$ is given by

$\left(\frac{k}{k_{0}}\right)^{1 / 3}=\frac{b_{0, \mathrm{e}}}{b_{0}}\left(1-\frac{\sigma_{\mathrm{n}}}{E_{\mathrm{F}, \mathrm{e}}}\right)+\frac{b_{0, \mathrm{t}}}{b_{0}} \exp \left(-\frac{\sigma_{\mathrm{n}}}{E_{\mathrm{F}, \mathrm{t}}}\right)$

where $k_{0}$ is permeability corresponding to $b_{0}$.

If the first term on the right hand of the above equation is ignored, the permeability relationship can be simplified as

$\left(\frac{k}{k_{0}}\right)^{1 / 3}=\exp \left(-\frac{\sigma_{\mathrm{n}}}{E_{\mathrm{F}, \mathrm{t}}}\right)$
The above equation essentially assumes that the entire fracture aperture is "soft." Given the fact that clay rock is generally viewed as soft rock, it seems logical to use Eq. 5 for fractures in clay rock. This is supported by a number of laboratory measurements that show linear relationships between the $\log$ of measured fracture permeability and stress (e.g., Blumling et al. 2007; Zhang and Rothfuchs 2008; Popp et al. 2008).

In all the above discussions, stress refers to effective stress. For a swelling rock, fracture effective stress is given as (Liu and Rutqvist 2010)

$\sigma=\sigma_{\mathrm{t}}-\alpha P+\sigma_{\mathrm{I}}$

where $\sigma_{\mathrm{t}}$ is the total stress, $P$ is the fluid pressure, $\alpha$ is the Biot's coefficient, and $\sigma_{\mathrm{I}}$ is an addition term called "internal swelling stress" that accounts for impacts of matrix swelling and is determined by (Liu and Rutqvist 2010):

$\sigma_{\mathrm{I}}=f \varepsilon_{\mathrm{S}} K_{\mathrm{M}}$

where $\varepsilon_{\mathrm{s}}$ is the matrix strain resulting from swelling, $K_{\mathrm{M}}$ is the bulk modulus for the clay matrix, $f$ is an empirical parameter with values to be determined by experiments.

\section{Data Analyses}

Several constitutive relationships for elastic deformation of clay rock were presented in Sect. 2. The current section will demonstrate the validity of these relationships by comparing the theoretical results with selected laboratory measurements. (Note that related parameters need to be determined empirically.)

\subsection{Stress-Strain Data of Opalinus Clay}

Corkum and Martin (2007) reported comprehensive laboratory measurements for the mechanical behavior of Opalinus clay (with a water content of $6.1 \%$ ) at low stress. The low-stress behavior is of interest because it is closely associated with unloading around tunnels and the resultant excavation damaged zone. A number of uniaxial and triaxial compression tests were performed, indicating significant nonlinear elastic deformation in the low stress region. Corkum and Martin (2007) suggest that the nonlinear behavior can be explained from clay's micro-structure, associated with diagenetic processes over the last 180 million years.

We use uniaxial test results to verify our stress-strain relation (Eq. 2), because more data are available for the uniaxial test condition. To do so, we need to replace volumetric strain with axial strain, and bulk modulus $(K)$ with the corresponding Young's modulus $(E)$ in Eq. 2. The test 


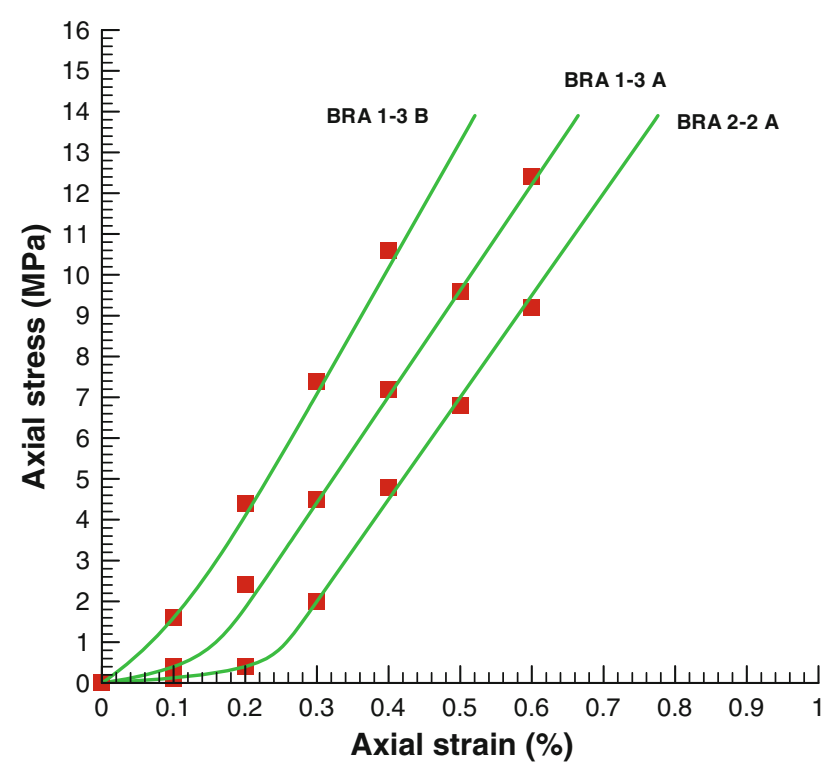

Fig. 1 Matches between laboratory measurements and Eq. 8 in which volumetric strain and a bulk modulus $(K)$ need to be replaced with axial strain and the corresponding Young's modulus $(E)$, respectively. The data points are measurements (Corkum and Martin 2007) and the solid curves are theoretical results

Table 1 Fitted mechanical parameters for Opalinus clay

\begin{tabular}{llll}
\hline Rock sample & $\gamma_{\mathrm{t}}(\%)$ & $E_{\mathrm{e}}(\mathrm{MPa})$ & $E_{\mathrm{t}}(\mathrm{MPa})$ \\
\hline BRA 2-2 A & 0.22 & $2,494.5$ & 0.22 \\
BRA 1-3 A & 0.13 & $2,596.6$ & 0.38 \\
BRA 1-3 B & 0.08 & $3,097.6$ & 0.65
\end{tabular}

results are given as axial stress as a function of axial strain and in excellent agreement with our theoretical results for samples BRA 2-2 A, BRA 1-3 A and BRA 1-3 B (Fig. 1). These samples are taken from boreholes BRA-1 and BRA-2 drilled at the Mont Terri site, Switzerland. Fitted parameter values are given in Table 1 .

\subsection{Water Permeability Measurements for a Macro-Cracked Argillite Sample}

Recently, Davy et al. (2007) reported laboratory measurements of single fractures within macro-cracked CallovoOxfordian argillite samples subject to both confinement and water-induced swelling. The data set provides a unique opportunity to examine our formulations for estimating fracture permeability as a function of effective stress that considers effects of swelling.

Figure 2 shows the test procedure in terms of changes in confining pressure and fracture closure for sample 2 (Davy et al. 2007). Although water permeability measurements were provided for two samples, we will analyze test results

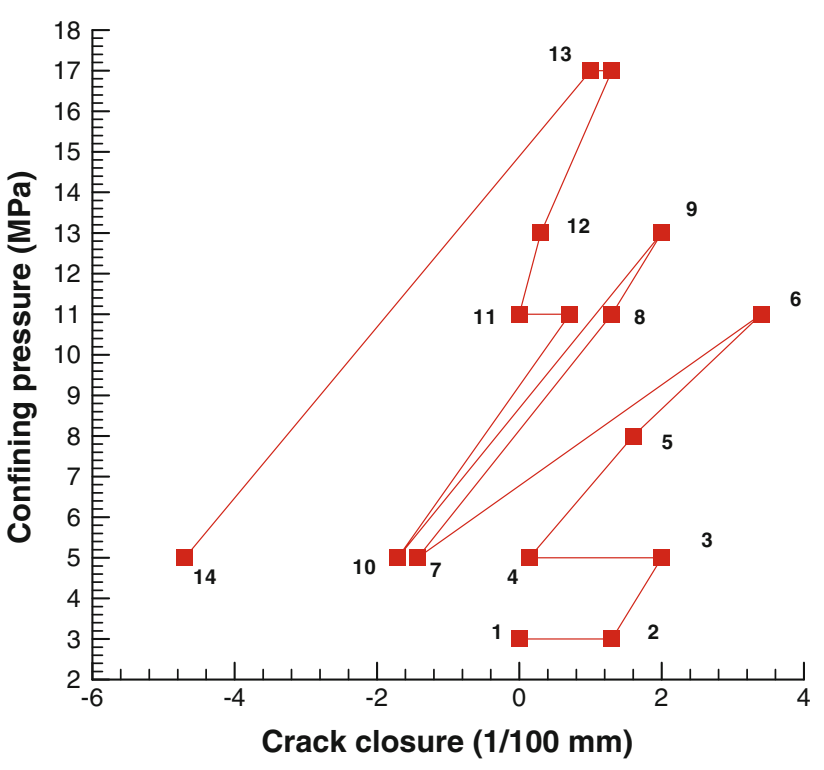

Fig. 2 Test procedure of water permeability measurement [in terms of confining pressure and fracture (crack) closure] for sample 2 of Davy et al. (2007). The numbers in the figure indicate the chronological order of points (C.A. Davy, personal communication). Since measured crack closure in Davy et al. (2007) is actually an effective parameter representing displacement of bulk rock sample, it can be positive or negative depending on the combination of confining pressure and swelling

for sample 2 only, because sample 2 is subject to a more complex test procedure. For a given confining pressure, the fracture closure increases from point 1 to 2 , which cannot be explained based on elastic deformation and is very likely due to plastic deformation at the beginning of the test. Therefore, our analysis will focus on data points after point 2. We also assume elastic deformation in that data range-mainly justified by the fact that our analysis based on the elastic deformation seems to be able to explain the majority of experimental observations. Also note that our Fig. 2 is identical to Fig 10(b) in Davy et al. (2007), except that we renumbered the chronological order of points such that they are consistent with those in Fig 12 of Davy et al. (2007), which present fracture permeability as a function of confining pressure (C.A. Davy, personal communication).

In Fig. 2, points 3, 4, 7, 10 and 14 correspond to the same confining pressure but with different amounts of swelling (measured as difference in crack closure between a given point and point 3 ). We believe that it is largely due to the transient behavior of water flow from fractures into the rock matrix. A longer time corresponds to a larger water penetration depth into the rock matrix near the fracture, and therefore to a larger rock volume involving swelling. Note that during the water permeability measurement, water was injected into the fracture. For simplicity, we assume that water penetration depth as a function of time can be described by the well-known 
infiltration theory developed by Philip (1957). Under ponding conditions on the ground surface, Philip's theory indicates that the cumulative amount of water infiltrating into unsaturated soil with a uniform initial water saturation is proportional to the square root of time. Consequently, if we view the fracture wall as the ground surface, then approximate the water penetration depth by the amount of accumulative infiltrating water (in depth) divided by the difference between saturated and initial water contents, and further assume that swelling within the water-penetrating zone is uniform and occurs simultaneously with water content changes, then the total swelling due to increase in water content, $S$ (in $10^{-2} \mathrm{~mm}$ ), will be proportional to water penetration depth, or

$S=A t^{1 / 2}$

where $A$ is a constant herein. The above equation (with $A=3.08 \mathrm{E}-2 \mathrm{~mm} / \mathrm{day}^{-1 / 2}$ ) seems to fit observed swelling for points $3,4,7,10$, and 14 (corresponding to different times) satisfactorily (Fig. 3), indicating that our above reasoning is reasonable. Note that the observed crack-closure value in Davy et al. (2007) is a combination of rock swelling and the corresponding change in fracture aperture. However, as a result of the low water permeability of fracture, the fracture aperture value (estimated from cubic law with the permeability value on the order of $1 \mathrm{E}-18 \mathrm{~m}^{2}$ ) is negligibly small, only on the order of $1 \mathrm{E}-3 \mathrm{~mm}$, as compared with observed crack closure. Therefore, the swelling is approximated by the observed crack closure.

When confining and pore pressures are constant, fracture permeability purely due to swelling may be obtained from Eqs. 5 and 6 and given as

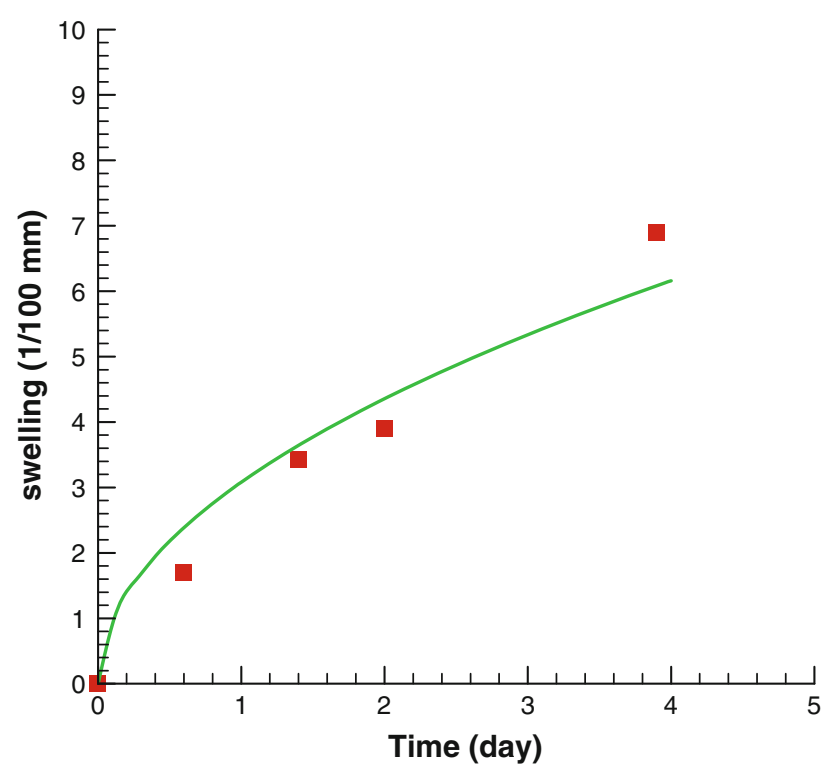

Fig. 3 Match between observed swellings for points (3, 4, 7, 10, and 14) with those calculated from Eq. 8 (solid curve) $\left(\frac{k}{k_{3}}\right)^{1 / 3}=\exp \left(-\frac{\Delta \sigma_{\mathrm{I}}}{K_{\mathrm{F}, \mathrm{t}}}\right)$

where $k_{3}$ is the permeability at point 3 and $\Delta \sigma_{\mathrm{I}}$ is the difference in internal swelling pressure between a given point and point 3. Using definition of the internal swelling stress (Eq. 7) together with Eq. 8, the difference in internal swelling pressure is given as

$\Delta \sigma_{\mathrm{I}}=f \varepsilon_{\mathrm{s}} K_{\mathrm{M}}=f K_{\mathrm{M}} \frac{S}{L}=\left(\frac{f K_{\mathrm{M}} A}{L E_{\mathrm{F}, \mathrm{t}}}\right) E_{\mathrm{F}, t} t^{1 / 2}=B E_{\mathrm{F}, t} t^{1 / 2}$

where $L$ is a characteristic length equivalent to fracture spacing, and $B$ is a constant. Combining Eqs. 9 and 10 yields

$\left(\frac{k}{k_{3}}\right)^{1 / 3}=\exp \left(-B t^{1 / 2}\right)$

Again, Eq. 11 fits the observations fairly well (Fig. 4).

Equation 11 is applicable only when confining pressure (or total stress) and the pore pressure of water in the fracture are constant. Pore pressure changes $(<0.7 \mathrm{MPa})$ are small compared to the changes in confining pressure in the water permeability experiments of Davy et al. (2007), and therefore can be ignored. In this case, a more general permeability relationship (that considers the effects of both confining pressure and swelling) can be obtained by combing Eqs. 5, 6 and 11:

$\left(\frac{k}{k_{3}}\right)^{1 / 3}=\exp \left(-\frac{\Delta \sigma_{\mathrm{t}}}{E_{\mathrm{F}, \mathrm{t}}}-B t^{1 / 2}\right)$

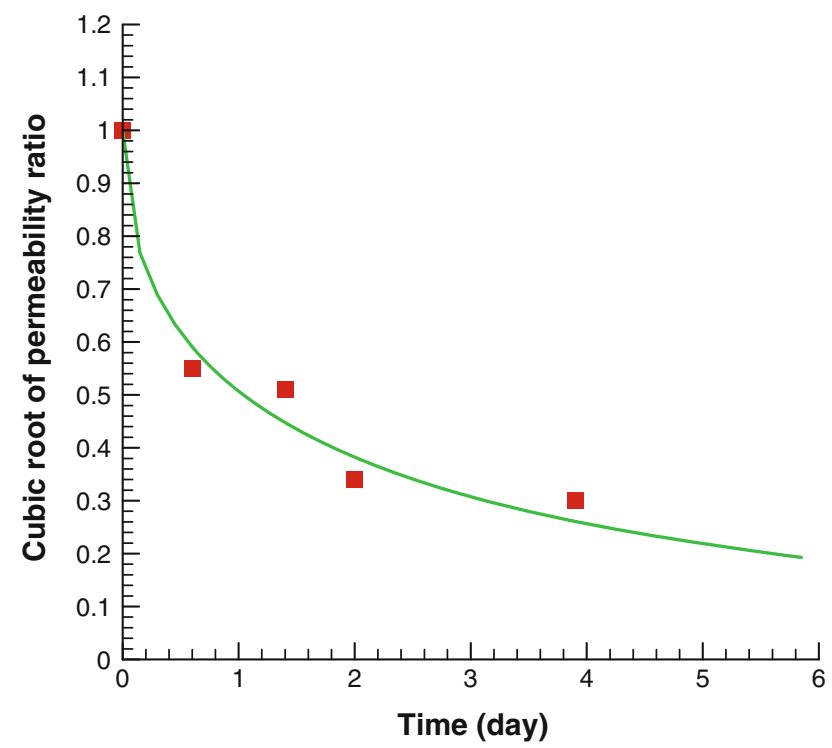

Fig. 4 Match between observed values for $\left(k / k_{3}\right)^{1 / 3}$ for points $(3,4,7$, 10 and 14) with those calculated from Eq. 11 (solid curve). The fitted $B$ value is 0.68 day $^{-1 / 2}$ 


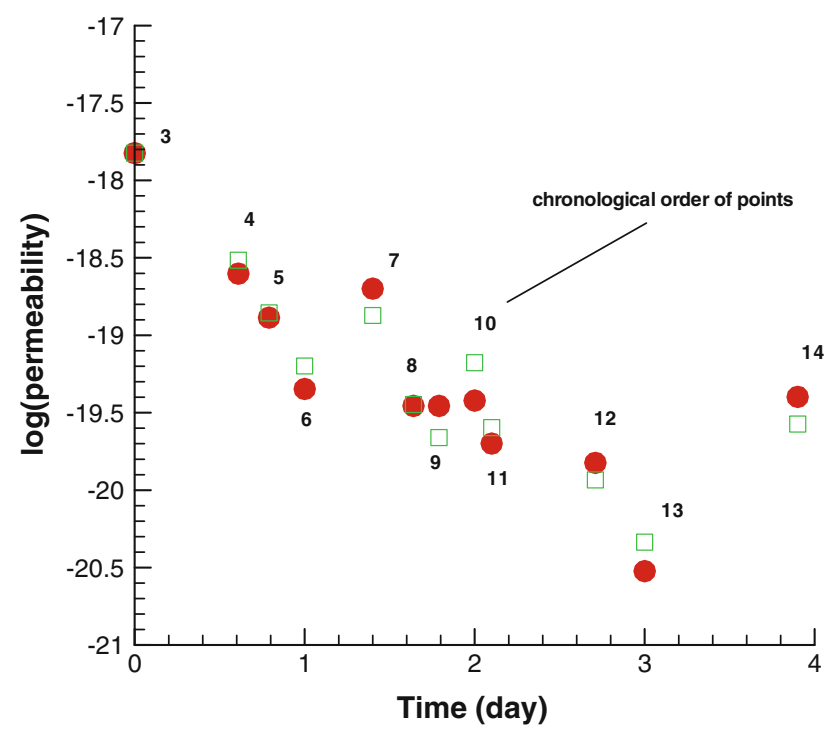

Fig. 5 Comparisons between observed and simulated fracture permeability changes as a function of time. The solid circles are measurements

The only unknown in the above equation is $E_{\mathrm{F}, \mathrm{t}}$ which can be estimated from the permeability data as a function of both confining pressure and time (Davy et al. 2007). The estimated (or fitted) $E_{\mathrm{F}}$ is $16 \mathrm{MPa}$. Figure 5 shows a comparison between measured and estimated permeability values as a function of time. Given the complexity of the experimental processes, the comparison is remarkable, supporting the validity of the relevant constitutive relationships.

Note that we ignore creeping processes in our data analysis, based on the consideration that permeability changes due to creeping are not expected to be significant in the experiments of Davy et al. (2007). For example, the laboratory experiments of Jobmann et al. (2010) showed that over about 5 days, fracture permeability was reduced by $20 \%$ only for Opalinus clay. This permeability change is much smaller than those observed in the experiments of Davy et al. (2007) (Fig. 5), although Opalinus clay is softer than the Callovo-Oxfordian argillite rock studied in Davy et al. (2007) and therefore subject to a larger degree of creeping.

\section{Concluding Remarks}

Several important constitutive relationships are proposed for indurated clay rock based on three recently developed concepts. First, when applying Hooke's law in clay rocks, true strain, rather than engineering strain, should be used, except when the degree of deformation is very small. Second, because of its inherent heterogeneity, clay rock can be divided into two parts (a hard part and a soft part) with different mechanical properties. Third, for swelling rock like clay, the effective stress needs to be generalized to include an additional term resulting from the swelling process.

To evaluate our theoretical development, we analyzed uniaxial test data for core samples of Opalinus clay and laboratory measurements for single fractures within macrocracked Callovo-Oxfordian argillite samples. The agreement between our theoretical results and data are remarkably reasonable, supporting the validity of our proposed constitutive relationships.

Open Access This article is distributed under the terms of the Creative Commons Attribution Noncommercial License which permits any noncommercial use, distribution, and reproduction in any medium, provided the original author(s) and source are credited.

\section{References}

Alonso EE, Alcoverro J (2002) Swelling and degradation of argillaceous rocks. In: Proceedings of the 3rd international conference on unsaturated soils, Recife, Brazil, vol 3, pp 951-969

Barnichon JD, Volckaert G (2003) Observations and predictions of hydromechanical coupling effects in the Boom clay, Mol Underground Research Laboratory, Belgium. Hydrogeol J 11(1):193-202

Blumling P, Bernier F, Lebon P, Martin CD (2007) The excavation damaged zone in clay formations time-dependent behavior and influence on performance assessment. Phys Chem Earth 32:588-599

Corkum AG, Martin CD (2007) The mechanical behavior of week mudstone (Opalinus clay) at low stress. Int J Rock Mech Min Sci 44:196-209

Davy CA, Skoczylas F, Barnichon JD, Lebon P (2007) Permeability of macro-cracked argillite under confinement: gas and water testing. Phys Chem Earth 32:667-680

Fouche O, Wright H, Cleach JL, Pellenard P (2004) Fabric control on strain and rupture of heterogeneous shale samples by using a non-conventional mechanical test. Appl Clay Sci 26:367-387

Jobmann M, Wilsnack Th, Voigt HD (2010) Investigation of damageinduced permeability of Opalinus clay. Int J Rock Mech Min Sci 46:279-285

Liu HH, Rutqvist J (2010) A new coal-permeability model: internal swelling stress and fracture matrix interaction. Transp Porous Med 82(1):157-171

Liu HH, Rutqvist J, Berryman JG (2009) On the relationship between stress and elastic strain for porous and fractured rock. Int J Rock Mech Min Sci 46:289-296

Meier P, Trick T, Blumling P, Volckaert G (2000) Self-healing of fractures within the EDZ at the Mont Terri rock laboratory: results after one year of experimental work. In: Proceedings of the international workshop on geomechanics, hydromechanical and thermomechanical behavior of deep argillaceous rocks: theory and experiments, Paris, 11-12 October

Patriarche D, Ledoux E, Simon-Coincon R, Michelot J, Cabrera J (2004) Characterization and modeling of diffusive process for mass transport through the Tournemire argillites Aveyron, France. Appl Clay Sci 26:109-122

Philip JR (1957) The theory of infiltration: 1 . The infiltration equation and its solution. Soil Sci 83:345-358 
Popp T, Salzer K, Minkley W (2008) Influence of bedding planes to EDZ-evolution and the coupled HM properties of Opalinus clay. Phys Chem Earth 33:5374-5387

Tsang CF, Bernier F, Davies C (2005) Geohydromechanical processes in the excavation damaged zone in crystalline rock, rock salt, and indurated and plastic clays-in the context of radioactive waste disposal. Int J Rock Mech Min Sci 42:109-125

Zhang CL, Rothfuchs T (2008) Damage and sealing of clay rocks detected by measurements of gas permeability. Phys Chem Earth 33:5363-5373 